\title{
The Curse of Realism: Cognitive Narratology and the
}

\section{Historical Dimension ${ }^{1}$}

\section{Karin Kukkonen}

University of Oslo

Few narratologists have argued as consistently for the need to take into account the historical development in narrative studies as has Monika Fludernik. Even fewer have pursued the diachronic dimension with the expertise that we find on display in Towards a 'Natural' Narratology (1996). Fludernik develops a sustained argument about historical developments from her cognitive model, tracing how literary narrative through the centuries progressively gets closer to matching the "schemata" of our cognitive processes. What we read on the page becomes more and more easily integrated into these schemata as literary style approaches what we call “realism.” Fludernik draws here on Jonathan Culler’s notion of “naturalization,” according to which readers make familiar what they read in a literary narrative by casting it in terms of their real-world expectations. Similarly, Fludernik suggests, readers engage in "narrativization” when they inscribe the novels they read into the narrative schemata that underlie our thinking. As the centuries go by, literary texts get progressively better at playing into these schemata and these narratives become progressively more "real” in terms of the "experientiality" that they convey.

\footnotetext{
* This article is a modified excerpt from Kukkonen, How the Novel Found Its Feet: Embodiment in EighteenthCentury Fiction (under review; with permission of the publisher).
} 
Early English novelists, like Aphra Behn (who is central for Fludernik) and Samuel Richardson, laid the foundation of realism in the novel through the foregrounding of linguistic strategies for portraying consciousness and experientiality, preparing the way for the features typical of the $19^{\text {th }}$-century novel. Fludernik explicitly excludes such $18^{\text {th }}$-century novelists as Eliza Haywood and Charlotte Lennox from this development. They had not caught on to the "extensive portrayal of consciousness" that would determine the novel's future: in their texts they "still imitate the dramatic soliloquy or use brief summarizing psychonarration” (170; my italics).

The cognitive master narrative of the historical development of the novel depends on the pull of realism, perhaps even more so than the traditional accounts of realism emerging in tandem with empirical interest in the everyday: the rise of the bourgeoisie and the beginnings of secularization, for which Ian Watt's The Rise of the Novel (1976 [1957]) still remains a touchstone. If the style of "realism" is the best possible textual match to the cognitive processes through which we understand the actual world, then modes of style and narration had to move toward what we call "realism" today, and it seems to be a matter of course that novelists would gradually discover this most fitting way to tell a story in the historical development of literary prose. For a cognitive account of the development of realism in the "rise of the novel," there seems to be something like a core trajectory of development with some slight deviations at particular points. It had to be you, realism.

Fludernik assesses Haywood and Lennox by standards that have come from the $19^{\text {th }}$-century realist novel, and her perspective on these authors depends on a phenomenon I call "the curse of realism." The curse of realism is akin to the "curse of knowledge” in the study of cognitive biases. If someone knows more than 
someone else, it is very hard to think in such a way as to take the position of the one who knows less. ${ }^{1}$ Only a very savvy car salesman (to take an example from the literature) can pretend that he does not know about the flaws of the car when he is well aware of them. It takes a very good teacher to put herself into the shoes of her students who do not know what the correct way of solving a math problem is when she herself has done these calculations innumerable times. Similarly, it is very hard for a literary critic to imagine a world in which the $19^{\text {th }}$-century realism of Flaubert and Eliot has yet to happen. The "curse of realism” falls back on a century that did not think of itself in such a way.

Here I want to keep with the spirit of Towards a 'Natural' Narratology and foreground the importance of considering distant texts historically from a cognitive perspective while arguing against the teleological pull that comes with the curse of realism. What does it take then, conceptually, to dispel the curse of realism? This may be possible once we move from the schema theory of first-generation cognitivism — the latest word when Towards a 'Natural' Narratology was published — to embodied, second-generation cognitive approaches and predictive processing which have come to the fore more recently in the cognitive sciences and neuroscience (see Friston 2012; Seth 2013) and philosophy (see Hohwy 2013; Clark 2015), and which enable us to revisit Fludernik’s concern with cognitive historicity today.

In order to divest from the notion that narrativization and naturalization recuperate texts for fixed schemata of "experientiality” (which the historically developing novel might then approach mimetically), let me outline the basic principles of predictive processing. This approach proposes that expectations (and our sense of the probabilities of the world around us) are constantly reconfigured in 
exchange with the sensory flow of the world. These predictions run across different levels of cognition. Do you expect your tea cup to be cold or hot to the touch? How far do you need to extend your arm to reach it (without looking) while you are sitting in your armchair? Perception and motor-sensory processes then feed into (and inform) conscious thought and actions on the basis of the predictive, probabilistic model. You might, for example, decide to get up and bring the tea cup closer to your seat to avoid calamity in reaching for the cup. The version of predictive processing which I favor here is decidedly embodied and depends on the physical situatedness of the mind-body in a material environment, which is navigated (and sometimes modified) on a predictive, probabilistic model (see Clark 2015). Contrary to first-generation schema theory, predictive processing stresses the continual flow of revising our expectations and the hierarchical cascades of feedback loops between levels of cognition. ${ }^{2}$ When you sit in your armchair and drink a cup of tea, your predictive, probabilistic model of the placement of the cup, heat of the beverage, etc. is revised in response to the sensory flow as you engage with the porcelain and tea.

Such a perspective allows us to move away from accounts that tie embodied cognition too closely to imitation and “embodied simulation.” Even though the embodied-cognition account suggests that readers experience a character's emotional turmoil through the embodied resonance of her bodily state, it seems wise to limit these bodily resonances to the minimal extent of mirror-neurons,, which would suggest that these resonances are (most likely) rather small-scale, local, and pre-conscious. With this limitation, we have a large gap between the embodied resonance and the overall narrative constellation in which these embodied resonances are embedded. If we follow Fludernik's account, then this gap 
can be bridged through the cognitive frames of EXPERIENCING which we match against the linguistic text. Indeed, Fludernik's historical account derives from these frames, because then, she suggests, literary texts become progressively "better" at evoking the frame of EXPERIENCING in readers as the mode of realism develops and “consciousness scenes” are fleshed out with free indirect discourse and descriptions of the "effet de réel.” Here, the frame of EXPERIENCING is a gold standard that seems to exist independently of the literary work of art — in the mind of the reader — and is approximated in the course of literary history. Fludernik’s stress clearly lies on "recuperation," where the mediation of literary fiction first represents "natural frames” and then "narrativizes” non-natural elements such as omniscient narration. For her, "the consciousness novel [is] the culmination point in the development of narrative realism," and it "naturalizes the unnatural (or rather, nonnatural) to perfection” (1996: 170).

Let us now have a closer look at Eliza Haywood's The History of Betsy Thoughtless (1751), one of the texts that, according to Fludernik, lag behind the general development toward realism. When Betsy sits alone in a garden, she looks lovingly at the portrait of her admirer, Mr. Trueworth. "At this instant, a thousand proofs of love given her by the original of the copy in her hand occurring all at once to her remembrance, tears filled her eyes, and her breast swelled with involuntary sighs” (Haywood 1998 [1751]: 606). The look at the mimetic imitation evokes memories and an emotional response in Betsy with strong bodily reactions, such as tears and sighs. The copy offers an emotional access back to the original, letting Betsy look through the layers of representation at what Mr. Trueworth actually means to her. Haywood integrates Betsy’s realization into the Aristotelian moment 
of "recognition" (anagnorisis) within the plot of her narrative. Indeed, it is not only Betsy Thoughtless who has a recognition.

In this painfully pleasing amusement did she continue for some time, and had doubtless done so much longer, if a sudden rustling among the leaves behind her had not made her turn her head to see what had occasioned it; -but where are the words that can express the surprize, the wild confusion she was in, when the first glance of her eyes presented her with the sight of the real object, whose image she had been thus tenderly contemplating. (606607)

Mr. Trueworth happens to be taking a walk in the park at exactly the moment when Betsy is looking at his portrait and confessing her love for him. When he observes this mimetic engagement, he himself realizes the true state of Betsy's affections. The double recognition then leads to the happy ending of the novel with the marriage between Betsy Thoughtless and Mr. Trueworth.

Haywood constructs a double recognition through the emotional reactions to the portrait of Mr. Trueworth, bringing together Betsy’s “involuntary sighs” with the highly contrived coincidence of Mr. Trueworth walking about in the gardens at exactly this moment. Haywood presents here an Aristotelian solution to her plot, where the turning point and recognition coincide (just as Aristotle had recommended in his Poetics). The constructedness of the coincidence is palpable in Haywood's novel, and it rejects “narrativization” and “naturalization” into realworld templates of experientiality. A second-generation cognitive perspective, which combines probabilistic and embodied aspects of cognition, stands in the 
Aristotelian tradition of mimesis as constructive and "world-creating” (see Halliwell 2002).

Readers of Eliza Haywood's Betsy Thoughtless may experience the state of “emotional turmoil” in which the heroine finds herself. It has been suggested, indeed, that the comprehension of language depends on the embodied resonances that words printed on a page can evoke in their readers (see Bergen [2012] for an accessible overview of work on this topic). Betsy’s eyes filling with tears and breasts swelling with sighs make sense to readers because of the embodied resonances which they evoke. So how do these embodied accounts of language comprehension relate to the artificiality of Haywood's narrative?

In predictive processing, the sensory flow that comes through embodied cognition feeds into our generative model of the probabilities of the world. Imagined processes engage the generative model, too. "That process of reconstruction [of the sensory signal] tuned and deployed in the presence of the sensory signal, paves the way for processes of outright construction, able to form and evolve in the absence of the usual sensory flow” (Clark 2015: 85). The predictive, probabilistic model can be revised and modified even while imagining or dreaming by "reconstructing the sensory signal using knowledge about interacting causes in the world” (ibid.). When you imagine a cup of tea, the sensory flow is absent. When you sit in your armchair and read about someone drinking a cup of tea, then there is a substitute for the sensory flow that comes not from your physical environment but from the words on the page. The words on the page supply a sensory flow that feeds the predictive generative model from motion verbs and descriptive and emotional states to cultural protocols and recognizable mimetic strategies. The literary text, then, can be understood as a designed sensory flow that 
guides the revision of the predictive, probabilistic model in particular ways. For that, however, it does not have to correspond to the sensory flow of the real world.

The probability design of sensory flow in a literary text stretches from embodied experience of the world across the reflective mind to socially and culturally defined character roles over the "cascades of cognition” (see Kukkonen 2014). The predictions and probabilities involved here are subjective assessments of how likely we think certain developments are (in the sense of Bayes) rather than objectively calculated frequencies (in the sense of Laplace). Such Bayesian predictions are at work in how the body expects the sensory-motor contingencies of the environment to respond to its movement (see Clark 2015; 2013), in how we make sense of another's actions within the expectations that we have of her behavior, and in how we make sense of our own emotional experience in the sense that it gets matched to our expectations of how we would react in a certain situation given our developed personal identity (see Seth 2013) — but perhaps also given the social role in which we see ourselves. Along these cascades of cognition, social roles can prefigure the way in which we conceive our experience and the emotional pattern through which we read our bodily states.

Accounts of predictive-processing have argued, among other things, that emotional experience depends on the interplay between interoception (the perception of bodily states) and the emotional templates and identity patterns. These allow us to predict what emotion we are likely to be feeling based on ways in which we have expressed them before, and also on ways in which we are likely to feel (see Seth 2013). Arguably, throughout history, cultural notions of the emotions have shaped the templates and identity patterns for these predictions in the process of emotion that Seth talks about. William Reddy (2001), for example, speaks of 
“protocols of emotions" which changed significantly between the $17^{\text {th }}$ and the $18^{\text {th }}$ centuries as the "passions” turn into "sentiments.” These protocols refer to the way in which emotions are conceptualized (in terms of "animal spirits” or "nervous" stimulations), to the way in which they are evaluated (as untameable "passions" or socially beneficial “sentiment”), and also to the practices through which they are enacted in social life. Pierre Bourdieu discusses these kinds of practices in terms of "habitus,” a phenomenon that has a distinctly embodied dimension (see Kukkonen 2016). If an emotional experience depends on the state "most likely to be me," as Seth would have it, then the "protocols of emotions" that are culturally and historically variable crucially influence how interoceptive states are experienced. In the designed sensory flow of the literary text, the predictions of embodiment, personal identity, and cultural protocols all work together.

In Haywood's prose Betsy’s emotional reaction is presented in strongly embodied and experiential terms, but it comes into effect only through a beautifully constructed recognition. Rather than a mere copy of reality, where characters and readers imitate the embodied appeal of motion verbs, bodily states, and directed movement, Haywood's prose transforms these elements of embodied experience into the articulated gestalt of the work of fiction or, in my terms, a designed sensory flow.

Haywood's recognition scene negotiates Plato’s and Aristotle’s conception of mimesis with the portrait as a Platonic “copy” of Trueworth (introduced earlier in the novel) and Aristotelian recognition (anagnorisis) in the plot. The scene also enacts the distinction between what Dror Wahrman calls the "ancient regime of identity” (2004), in which character is "legible” in terms of roles and attributes (Betsy plays the role of the coquette), and modern identity, in which the mind runs 
deeper (Betsy’s and Trueworth's realization about the state of their emotions). Probability design touches on all levels of the scene in Haywood. It involves Betsy’s embodied response to Mr. Trueworth’s image (and her likely state of emotional involvement), her projected role in society (and her likely sincerity as a coquette), and readers' expectations about a happy resolution of the narrative. At the beginning of Betsy Thoughtless, the heroine’s social image as a coquette determines the way in which readers and characters read her character. Later on, when she is abused by her husband and comes to regret the role she played earlier, her inner feelings come to the fore, and these contradict her legible character as “coquette.” Haywood's recognition scene then shifts the inner feelings (or the modern motivation of probability) into the foreground against the legibility of social roles (or the ancient regime of probability) and brings about the happy ending. In The History of Betsy Thoughtless, Haywood employs classical recognition through the portrait (in which one might realize the true family relation to another character or that one is the true heir to a fortune) in order to bring about a more modern recognition (in which one realizes the true state of one's feelings).

In the predictive-processing model that I propose here, neither of these two recognitions is more "natural” than the other. Literary texts do not so much imitate natural cognitive processes as work with readers' predictions in that they supply a designed sensory flow with the "articulated gestalt" of fiction. ${ }^{3}$ The designed sensory flow enables readers to grasp the embodied state of characters, a shift in identity regimes (ancient to modern), and a poetological argument about mimesis as it reconfigures the readers' predictive, probabilistic model.

The passage in Haywood, however, tells the recognition twice: first, as we have seen, through a brief soliloquy from Betsy and the embodied description of her 
response to the portrait; and then, for a second time, from the perspective of $\mathrm{Mr}$. Trueworth.

[She] betrayed agitations he had never seen in her before, he was impatient to discover if possible the motive, - he therefore advanced as gently as he could towards the back of the arbour, which having no woodwork, and the leafy canopy only supported by ozier boughs, placed at a good distance from each other, he had a full opportunity of beholding all that the reader has been told: - but what was his amazement to find it was his own picture, which had been taken from the painter's, was the object of her meditations! (607-608)

While the first recognition scene in Betsy Thoughtless “imitates the dramatic soliloquy or uses brief summarising psycho-narration” (Fludernik 1996: 170) in a mode that does not point forward to realism, the second recognition scene approaches “the consciousness novel," which Fludernik's historical account of cognitive narratology considers "the culmination point of narrative realism" because here "the perfection of the VIEWING and EXPERIENCING frames . . . allow for the easy recuperation (naturalization) of story matter as if through the eyes of a fictional consciousness” (ibid.). In this second case, Mr. Trueworth’s perception, and his inner speech (perhaps even FID in the final sentence), are foregrounded along the lines of what Fludernik would consider a "consciousness scene.” Haywood is not only "still imitating" modes of narration that have fallen by the wayside on the road to realism here, but she also contrasts them with what Fludernik considers the more advanced option. Does Haywood enact the historical 
development from earlier, artificial modes of prose-writing to later, realist modes in Betsy Thoughtless?

Arguably not, since the chapter in question ends with the remark that Betsy’s emotions and subsequent refusal of Mr. Trueworth are "an opportunity of shewing the command she had over herself” (610) — and with a couplet from Richard Escourt's play The Fair Example; Or the Modish Citizens (1706). All of this underlines the artificial, contrived nature of the scene rather than inviting narrativization. Writers like Haywood understood the novel as a literary genre that shapes and constructs our perception of reality rather than merely reproducing it. Moreover, $18^{\text {th }}$-century readers were not merely expected to narrativize and naturalize these highly experimental narratives but rather to appreciate their constructedness and invitation to complex thought about emotion, identity and the very principles of mimesis (as we saw foor the case of Haywood). Cognitive narratology seems to have difficulty in capturing such an understanding of the text and its historical formations because they cannot be reduced to a better or worse fit to the cognitive universals.

The problem here runs deep and indicates that a comprehensive shift between first- and second-generation cognitive approaches still awaits completion with respect to the ways in which these approaches conceptualize the relation between culture and cognition. Fludernik begins Towards a 'Natural' Narratology with a "Prologue in the Wilderness" in which she takes up poststructuralist notions about the essential distinction between the real and the cultura or/constructed. Anything we express in language is (always already, as Barthes would say) a construction. In that sense, Fludernik claims that the mimetic component of her theory is "radically constructed," and it seems that the best we can hope for is to 
create a construction that matches the cognitive build-up as closely as possible and can thus be easily narrativized. Fludernik is not the only cognitive literary scholar to rely on such an understanding of cognition. Emily Troscianko’s (2014) notion of “cognitive realism” similarly suggests that prose writing aims to work toward a good fit with the human cognitive build-up. In her case, however, what is considered to follow the norms of "realism" in the novel (such as specified settings, etc.) might not be cognitively realist. The pictorialist dominant of conventional realism is replaced by the embodied dominant of authors such as Kafka, who created an experiential realism during the reading process. David Herman opposes the "exceptionality thesis" in his preface to The Emergence of Mind (8). According to him, the literary text is not independent of our cognitive operations but draws on and feeds off everyday cognition which, in turn, provides access to the literary text in reading. Arguably, even in Herman's perspective, the text needs to be designed in such a way that it matches the cognitive parameters. Cultural constructedness needs to "recuperate" and "match" the prior level of cognition. These cognitive accounts would have to distinguish between the two versions of recognition in Haywood in terms of a looser and a closer fit to cognitive universals. Such an approach is problematic in that it drives a wedge between the different embodied strategies at play in Haywood, separating what seems to me a clearly unified writerly design.

The issue here, I think, lies in the conceptualization of the relationship between culture and cognition. In all these cases, there is the sense that culture and its constructions aim for, but never quite reach, the natural state of cognition. Second-generation approaches to cognition, which foreground the embodied, emotional, extended, and enactive nature of cognition, might allow us to rethink the 
issue. In this account, culture does not model itself after cognition but co-evolves with it. We enter an accelerating see-saw in which culture and cognition boost each other. Cognitive capacities and the bodily communicative mechanism of gestures and voice have enabled the development of language. The cultural achievements of language, in turn, allow human thought to abstract and amplify its reach in new ways (see Clark 2006). Writing, again, depends on the cognitive and bodily equipment of mankind, but it allows cognition to go much further than it could go without this cultural achievement (see Menary 2007). In the co-evolution of culture and cognition (see Wheeler and Clark 2008; Sterelny 2003), culture does not attempt to catch up with cognition; rather it is essentially integrated within it.

We can extend the co-evolutionary account of culture and cognition by considering literary narrative as the next swing on the see-saw, with the "articulated gestalt” of probability-designs catapulting human thought beyond the level of written, factual texts. Haywood's Betsy Thoughtless, for example, enables new, complex ways for thinking through and experiencing cultural templates of identity, along with the embodied appeal of her prose and poetological concerns in the fictional constellation of her recognition scene.

A cognitive narratology emerging from notions of the co-evolution of culture and cognition, modelled on predictive processing, does not conceive of the history of literary style as a trajectory toward realism. On this model, there is no pre-linguistic, pre-writing state of cognition that the literary text would need to work toward imitating. The mind itself is cultured, so to speak, and fictional narrative is one of the ways in which the co-evolution of cognition and culture plays out. As the probability design of the text provides the sensory flow that feeds the generative model, different styles of embodiment can be accommodated with none 
of them having a particular claim to greater and lesser "realism" or advancement on a historical trajectory. Cognitive narratology can move from a teleological model to an account of literary history that supports a dialectics between styles, poetic principles, and cultural protocols.

\section{Works Cited}

Bergen, Benjamin. 2012. Louder than Words: The New Science of How the Mind Makes Meaning. New York: Basic Books.

Camerer, Colin, George Loewenstein, and Martin Weber. 1989. “The Curse of Knowledge in Economic Settings: An Experimental Analysis.” The Journal of Political Economy 97/5: 1232-54.

Clark, Andy. 2006. "Beyond the Flesh: Some Lessons from a Mole Cricket.” June. https://www.era.lib.ed.ac.uk/handle/1842/1304 (June 5, 2017)

—. 2013. "Whatever Next? Predictive Brains, Situated Agents, and the Future of Cognitive Science.” Behavioral and Brain Sciences 36/3: 181-204.

—. 2015. Surfing Uncertainty: Prediction, Action, and the Embodied Mind. Oxford: Oxford University Press.

Fludernik, Monika. 1996. Towards a 'Natural' Narratology. London: Routledge.

—. 2014. “Afterword.” Style 48/3: 404-10.

Friston, Karl. 2012. “Prediction, Perception and Agency.” International Journal of Psychophysiology 83/2: 248-52.

Halliwell, Stephen. 2002. The Aesthetics of Mimesis: Ancient Texts and Modern Problems. Princeton: Princeton University Press.

Haywood, Eliza. 1998 [1751]. The History of Miss Betsy Thoughtless. Peterborough, Ont.: Broadview Press. 
Herman, David, ed. 2011. The Emergence of Mind: Representations of Consciousness in Narrative Discourse in English. Lincoln: University of Nebraska Press, pp. 1-40.

Hohwy, Jakob. 2013. The Predictive Mind. Oxford: Oxford University Press. Kukkonen, Karin. 2014. "Presence and Prediction: The Embodied Reader’s Cascades of Cognition.” Style 48/3: 367-84. -. 2016. “Bayesian Bodies: The Predictive Dimension of Embodied Cognition and Culture.” In The Cognitive Humanities, ed. Peter Garratt. Basingstoke: Palgrave Macmillan, pp. 153-67.

—. forthcoming. How the Novel Found its Feet: Embodiment in EighteenthCentury Fiction.

—. under review. Probability Designs: Literature and Predictive Processing. Kukkonen, Karin, and Henrik Skov Nielsen. forthcoming. “Fictionality.” Poetics Today

Menary, Richard. 2007. “Writing as Thinking.” Language Sciences 29/5: 621-32.

Reddy, William M. 2001. The Navigation of Feeling: A Framework for the History of Emotions. Cambridge: Cambridge University Press.

Seth, Anil K. 2013. “Interoceptive Inference, Emotion, and the Embodied Self.” Trends in Cognitive Sciences 17/11: 565-73.

Sterelny, Kim. 2003. Thought in a Hostile World: The Evolution of Human Cognition. Malden, MA: Blackwell.

Tobin, Vera. 2009. ““Cognitive Bias and the Poetics of Surprise.” Language and Literature 18/2: 155-72.

Troscianko, Emily. 2014. Kafka's Cognitive Realism. Routledge Studies in Rhetoric and Stylistics. New York: Routledge. 
Wahrman, Dror. 2004. The Making of the Modern Self: Identity and Culture in Eighteenth-Century England. New Haven: Yale University Press.

Watt, Ian. 1976 [1957]. The Rise of the Novel: Studies in Defoe, Richardson and Fielding. London: Chatto and Windus.

Wheeler, Michael, and Andy Clark. 2008. “Culture, Embodiment and Genes: Unravelling the Triple Helix.” Philosophical Transactions: Biological Sciences 363 (1509): 3563-75.

${ }^{1}$ The classic paper establishing the concept of the "curse of knowledge" is Camerer, Loewenstein, and Weber 1989. Tobin (2009) connects the "curse of knowledge” to the role of cognitive biases in understanding literary texts (through blending theory).

${ }^{2}$ In Towards a 'Natural' Narratology, Fludernik relies heavily on frame theory, and she has also endorsed the approach more recently (see Fludernik 2014). Insofar as frames and scripts yield predictions, they can be related to the predictive, probabilistic models of the world featured in predictive processing. However, there is no sense of the fluid dynamics between embodied predictions, cultural templates, and textual conventions that we have observed in the discussion of the example from Betsy Thoughtless. Fludernik assumes a transhistorical continuity of these very large frames, whereas predictive processing would stress that these frames are assembled on an ad-hoc basis (see Clark 2015); this becomes a central feature of a literary treatment of predictive processing (see Kukkonen under review). Fludernik’s process of “narrativization” in which the linguistic surface of literary texts matches the frames of everyday, natural cognition is largely uni-directional and can consider only as a limit case the exchanges between expectations and prediction errors that are at the heart of predictive processing. Frame theory (and 
Fludernik’s model) are certainly compatible with predictive processing, but they posit very different points of emphasis.

${ }^{3}$ The term is Wolfgang Iser’s. See Kukkonen and Nielsen (forthcoming) for a more detailed discussion of the relevance of Iser's account for second-generation cognition approaches. 